\title{
Response of the Antarctic stratosphere to warm pool El Niño Events in the GEOS CCM
}

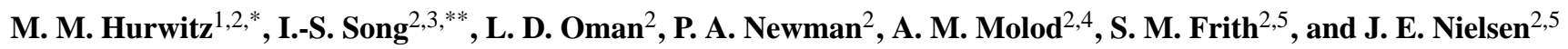 \\ ${ }^{1}$ NASA Postdoctoral Program, NASA Goddard Space Flight Center, Greenbelt, MD, USA \\ ${ }^{2}$ NASA Goddard Space Flight Center, Greenbelt, MD, USA \\ ${ }^{3}$ Goddard Earth Sciences and Technology Center (GEST), University of Maryland, Baltimore County, Baltimore, MD, USA \\ ${ }^{4}$ Earth System Science Interdisciplinary Center (ESSIC), University of Maryland, College Park, College Park, MD, USA \\ ${ }^{5}$ Science Systems and Applications, Inc., Lanham, MD, USA \\ *now at: NASA Goddard Earth Sciences Technology and Research (GESTAR), Morgan State University, Baltimore, \\ MD, USA \\ ** now at: Next Generation Model Development Project, Seoul, South Korea
}

Received: 2 March 2011 - Published in Atmos. Chem. Phys. Discuss.: 23 March 2011

Revised: 11 August 2011 - Accepted: 5 September 2011 - Published: 19 September 2011

\begin{abstract}
The Goddard Earth Observing System ChemistryClimate Model, Version 2 (GEOS V2 CCM) is used to investigate the response of the Antarctic stratosphere to (1) warm pool El Niño (WPEN) events and (2) the sensitivity of this response to the phase of the QBO. A new formulation of the GEOS V2 CCM includes an improved general circulation model and an internally generated quasi-biennial oscillation (QBO). Two 50-yr time-slice simulations are forced by repeating annual cycles of sea surface temperatures and sea ice concentrations composited from observed WPEN and neutral ENSO (ENSON) events. In these simulations, greenhouse gas and ozone-depleting substance concentrations represent the present-day climate. The modelled responses to WPEN, and to the phase of the QBO during WPEN, are compared with NASA's Modern Era Retrospective-Analysis for Research and Applications (MERRA) reanalysis.

WPEN events enhance poleward tropospheric planetary wave activity in the central South Pacific region during austral spring, leading to relative warming of the Antarctic lower stratosphere in November/December. During the easterly phase of the QBO (QBO-E), the GEOS V2 CCM reproduces the observed $4-5 \mathrm{~K}$ warming of the polar region at $50 \mathrm{hPa}$, in the WPEN simulation relative to ENSON.

In the recent past, the response to WPEN events was sensitive to the phase of the QBO: the enhancement in plane-
\end{abstract}

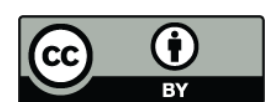

Correspondence to: M. M. Hurwitz (margaret.m.hurwitz@nasa.gov) tary wave driving and the lower stratospheric warming signal were mainly associated with WPEN events coincident with QBO-E. In the GEOS V2 CCM, however, the Antarctic response to WPEN events is insensitive to the phase of the QBO: the modelled response is always easterly QBO-like. The QBO signal does not extend far enough into the lower stratosphere and upper troposphere to modulate convection and thus planetary wave activity in the south central Pacific.

\section{Introduction}

Recent literature has identified two types of El Niño events. Conventional or "cold tongue" El Niño (CTEN) events are characterized by positive sea surface temperature (SST) anomalies in the eastern equatorial Pacific (Niño 3 region) (Rasmusson and Carpenter, 1982; Kug et al., 2009), while "warm pool" El Niño (WPEN) events are characterized by positive SST anomalies in the central equatorial Pacific (Niño 4 region) (Larkin and Harrison, 2005; Ashok et al., 2007; Kug et al., 2009).

The Northern Hemisphere (NH) stratosphere response to CTEN events is well recognized. El Niño-related warming of the Arctic stratosphere has been identified in both observational (Bronnimann et al., 2004; Free and Seidel, 2009) and modelling studies (Sassi et al., 2004; Manzini et al., 2006; Cagnazzo et al., 2009). This warming is a response to increased planetary wave driving: Garfinkel and Hartmann

Published by Copernicus Publications on behalf of the European Geosciences Union. 
(2008) showed that the extra-tropical tropospheric teleconnections produced during El Niño events weaken the Arctic vortex, leading to higher stratospheric temperatures during the NH winter season. Furthermore, the phase of the quasibiennial oscillation (QBO) modulates the stratospheric response to CTEN: The Arctic vortex is weakest in years when CTEN events coincide with the easterly phase of the QBO (Garfinkel and Hartmann, 2007).

Hurwitz et al. (2011) identified a robust response to WPEN in the Southern Hemisphere (SH) spring and summer. Using meteorological reanalyses, the authors showed the poleward extension and increased strength of the South Pacific Convergence Zone SPCZ during WPEN events, as compared with ENSO neutral (ENSON), in austral spring. The configuration of convective activity in the south Pacific during WPEN events favoured an enhancement of planetary wave activity in the upper troposphere. In austral summer, higher polar stratospheric temperatures and a weakening of the Antarctic polar jet were observed.

The phase of the QBO modulates the strength of the Antarctic vortex in austral spring and summer (Baldwin and Dunkerton, 1998). Analogously to the NH response to CTEN events, Hurwitz et al. (2011) found the SH response to WPEN events to be dependent on the phase of the QBO: planetary wave driving was strongest in WPEN years coincident with the easterly phase of the QBO. However, the SH response to ENSO neutral events was insensitive to the phase of the QBO (Hurwitz et al., 2011).

While the conclusions reached by Hurwitz et al. (2011) were based on physical arguments, statistically robust, and consistent amongst several reanalysis datasets, the scope of the authors' study was limited by the small number of WPEN events during the satellite era. In particular, the WPEN and easterly QBO composite consisted of just three events. Hurwitz et al. (2011) concluded that simulations forced by repeating WPEN and ENSON boundary conditions would greatly increase the sample size and strengthen their findings. Such simulations require a model with a well-resolved stratosphere, a QBO, and because the stratospheric response to WPEN occurs in austral spring and summer, interactive polar ozone chemistry.

This paper presents the first attempt to simulate the $\mathrm{SH}$ stratospheric response to WPEN events. Section 2 describes the atmospheric datasets and time-slice simulations with the Goddard Earth Observing System Chemistry-Climate Model, Version 2 (GEOS V2 CCM) to be analysed. In Section 3, OLR, tropospheric stationary wave patterns, a Rossby wave source diagnostic, eddy heat flux at $100 \mathrm{hPa}$ and stratospheric temperatures illustrate the observed and modelled responses to WPEN events, as well as modulation of the WPEN response by the QBO. Section 4 provides a summary of the results and a brief discussion.

\section{Model and data sources}

\subsection{Atmospheric datasets}

The Modern Era Retrospective-Analysis for Research and Applications (MERRA) is used to calculate streamfunction, eddy heat flux, temperature, wind and planetary wave energy diagnostics for the 1979-2009 period. MERRA is a reanalysis dataset based on an extensive set of satellite observations and on the Goddard Earth Observing System Data Analysis System, Version 5 (GEOS-5) (Bosilovich et al., 2008; Rienecker et al., 2011). The MERRA reanalysis has vertical coverage up to $0.1 \mathrm{hPa}$, and for this study, is interpolated to $1.25^{\circ} \times 1.25^{\circ}$ horizontal resolution. Hurwitz et al. (2011) showed that the response to WPEN was consistent amongst several meteorological reanalyses, including MERRA.

Zonal winds from the MERRA reanalysis are used to characterize the phase of the QBO. For each year between 1979 and 2009, November/December mean zonal winds at $50 \mathrm{hPa}$, between $10^{\circ} \mathrm{S}$ and $10^{\circ} \mathrm{N}$, form a QBO index: QBO easterly years (QBO-E) are identified when the QBO index is less than $-2 \mathrm{~m} \mathrm{~s}^{-1}$; QBO westerly years $(\mathrm{QBO}-\mathrm{W})$ are identified when the QBO index is larger than $2 \mathrm{~m} \mathrm{~s}^{-1}$.

Outgoing longwave radiation (OLR) between 1979 and 2009 is obtained from the NOAA interpolated OLR dataset (Liebmann and Smith, 1996), provided by NOAA/OAR/ESRL Physical Sciences Division, Boulder, CO.

WPEN and ENSON events are identified using SON seasonal mean SST anomalies in the Niño 3 and Niño 4 regions (http://www.cpc.noaa.gov/data/indices), as in Hurwitz et al. (2011). Because of the anomalous conditions in the SH stratosphere during the 2002 winter season (i.e., Newman and Nash, 2005), the 2002-2003 WPEN event has been excluded from the present analysis. The observed WPEN and ENSON events considered in the following analysis are listed in Table 1. Three WPEN events are coincident with QBO-E (WPEN/QBO-E) and three are coincident with QBO-W (WPEN/QBO-W). 12 ENSON events are distributed throughout the satellite era.

\subsection{A new formulation of the GEOS V2 CCM}

The GEOS V2 CCM couples the GEOS-5 general circulation model (GCM) with a comprehensive stratospheric chemistry module (Bloom et al., 2005; Pawson et al., 2008). The model has $2^{\circ}$ latitude $\times 2.5^{\circ}$ longitude horizontal resolution and 72 vertical layers, with a model top at $0.01 \mathrm{hPa}$. Predicted distributions of water vapour, ozone, greenhouse gases $\left(\mathrm{CO}_{2}\right.$, $\mathrm{CH}_{4}$, and $\mathrm{N}_{2} \mathrm{O}$ ) and CFCs (CFC-11 and CFC-12) feedback to the radiative calculations. The performance of the GEOS V2 CCM was evaluated in detail by SPARC CCMVal (2010). The present study considers a new formulation of the GEOS V2 CCM, with an updated GCM and a new gravity wave drag scheme. 
Table 1. List of ENSO events composited to create the SST and sea ice boundary conditions for the WPEN and ENSON simulations. The years shown refer to the SON season included for each event. * symbols denote QBO-E years; ** symbols denote QBO-W years.

\begin{tabular}{|c|c|c|c|c|c|c|c|c|}
\hline \multirow[b]{2}{*}{ WPEN } & \multicolumn{4}{|c|}{ MERRA Composites } & \multicolumn{4}{|c|}{$\begin{array}{l}\text { Events Composited to Create } \\
\text { Boundary Conditions for GEOS } \\
\text { CCM Simulations }\end{array}$} \\
\hline & $\begin{array}{l}1986 \\
2004^{* *}\end{array}$ & $\begin{array}{l}1991^{*} \\
2006^{* *}\end{array}$ & $\begin{array}{l}1994^{*} \\
2009^{* *}\end{array}$ & $2003^{*}$ & $1991^{*}$ & $1994^{*}$ & & \\
\hline ENSON & $\begin{array}{l}1979^{*} \\
1989^{*} \\
2000\end{array}$ & $\begin{array}{l}1980^{* *} \\
1992^{*} \\
2001^{*}\end{array}$ & $\begin{array}{l}1981^{*} \\
1993^{* *} \\
2005^{*}\end{array}$ & $\begin{array}{l}1985^{* *} \\
1996^{*} \\
2008^{* *}\end{array}$ & $\begin{array}{l}1979^{*} \\
1989^{*} \\
2001^{*}\end{array}$ & $\begin{array}{l}1980^{* *} \\
1992^{*} \\
2005^{*}\end{array}$ & $\begin{array}{l}1981^{*} \\
1993^{* *}\end{array}$ & $\begin{array}{l}1985^{* *} \\
1996^{*}\end{array}$ \\
\hline
\end{tabular}

The present version of the GEOS-5 GCM uses the finitevolume dynamics of Lin (2004). Physical parameterizations include schemes for atmospheric convection, largescale precipitation and cloud cover, longwave and shortwave radiation, turbulence, gravity wave drag, as well as a land surface model. Convection is parameterized using the Relaxed Arakawa-Schubert (RAS) scheme (Moorthi and Suarez, 1992) and a scheme for the re-evaporation of falling rain (Bacmeister, 2006). RAS is a mass flux scheme with an updraft-only detraining plume cloud model and a quasiequilibrium closure. The longwave radiative processes are described by Chou et al. (2001), and include absorption due to cloud water, water vapour, carbon dioxide, ozone, $\mathrm{N}_{2} \mathrm{O}$ and methane. The shortwave radiative scheme follows Chou and Suarez (1999), and includes absorption by water vapour, ozone, oxygen, $\mathrm{CO}_{2}, \mathrm{CH}_{4}, \mathrm{~N}_{2} \mathrm{O}, \mathrm{CFC}-11, \mathrm{CFC}-12$ and HCFC-22, as well as scattering by cloud water and aerosols. The turbulence parameterization is based on the Lock (2000) scheme, acting together with the Richardson-number based scheme of Louis et al. (1982). The Monin-Obukhov surface layer parameterization is described in Helfand and Schubert (1995). The Koster et al. (2000) land surface model is a catchment-based scheme that defines two soil layers for temperature, three soil layers for moisture, a snow pack and a canopy interception reservoir.

A previous version of the GEOS-5 GCM was used as part of MERRA, as described in Rienecker et al. (2011). Major changes to the moisture, turbulence and gravity wave drag schemes were made from this previous model version (Molod et al., 2011). Increased re-evaporation of grid scale and convective precipitation, along with modifications to the turbulence parameterizations to limit the impact of the Lock scheme and enhance the impact of the Louis scheme in the presence of wind shear, improved the simulated tropical convergence and convection patterns, as well as the global stationary wave patterns (Molod et al., 2011). As noted by Hurwitz et al. (2010), the representation of tropospheric stationary wave patterns determines a model's ability to simulate eddy heat flux at $100 \mathrm{hPa}$.
The model's gravity wave parameterization (GWP) computes the momentum and heat deposition to the breaking of orographic and non-orographic gravity waves using the linear saturation theory by Lindzen (1981). Orographic gravity wave stress is specified using the formulation derived by McFarlane (1987) and given at the top of the subgrid-scale mountains. Subgrid-scale orography is assumed to be horizontally isotropic, and hence the orographic wave stress is oriented opposite to the wind direction averaged below the top of the subgrid mountains. Non-orographic wave stress is given as a Gaussian-shaped phase speed spectrum at $400 \mathrm{hPa}$; phase speeds are assumed to be parallel to the wind direction at $400 \mathrm{hPa}$. The spectrum is composed of 9 waves with ground based phase speeds ranging from -40 to $40 \mathrm{~m} \mathrm{~s}^{-1}$ at an interval of $10 \mathrm{~m} \mathrm{~s}^{-1}$, as in Garcia and Solomon (1985). As non-orographic gravity waves often accompany precipitation (e.g., convective and frontal systems; see Richter et al., 2010), the latitudinal structure of the gravity wave spectrum is designed to mimic the structure of the climatological mean precipitation field: The spectrum maximizes $\left(7.7 \times 10^{-3} \mathrm{~N} \mathrm{~m}^{-2}\right)$ at the equator, has two secondary maxima of $2 \times 10^{-3} \mathrm{~N} \mathrm{~m}^{-2}$ at $60^{\circ} \mathrm{N}$ and $60^{\circ} \mathrm{S}$, and is weakest at subtropical latitudes. The tropical peak in non-orographic gravity wave stress is necessary for the generation of an internal QBO in the model (as in Ziemke et al., 2010; see also Sect. 3.1).

In the Lindzen-based scheme, the horizontal wavelength is $100 \mathrm{~km}$ both for orographic and non-orographic waves. A $700 \mathrm{~km}$ wavelength is used for the tropical non-orographic waves to prevent an excessive downward propagation of the semi-annual oscillation into the lower stratosphere, and thus contamination of the QBO signal. The intermittency factor is doubled for orographic waves south of the $40^{\circ} \mathrm{S}$, based on the observations of strong mountain waves from the Antarctic peninsula (Alexander and Teitelbaum, 2007) and isolated small islands (Alexander et al., 2009). This increased intermittency factor is effective in producing a reasonable evolution of the breakup of the Antarctic vortex. 

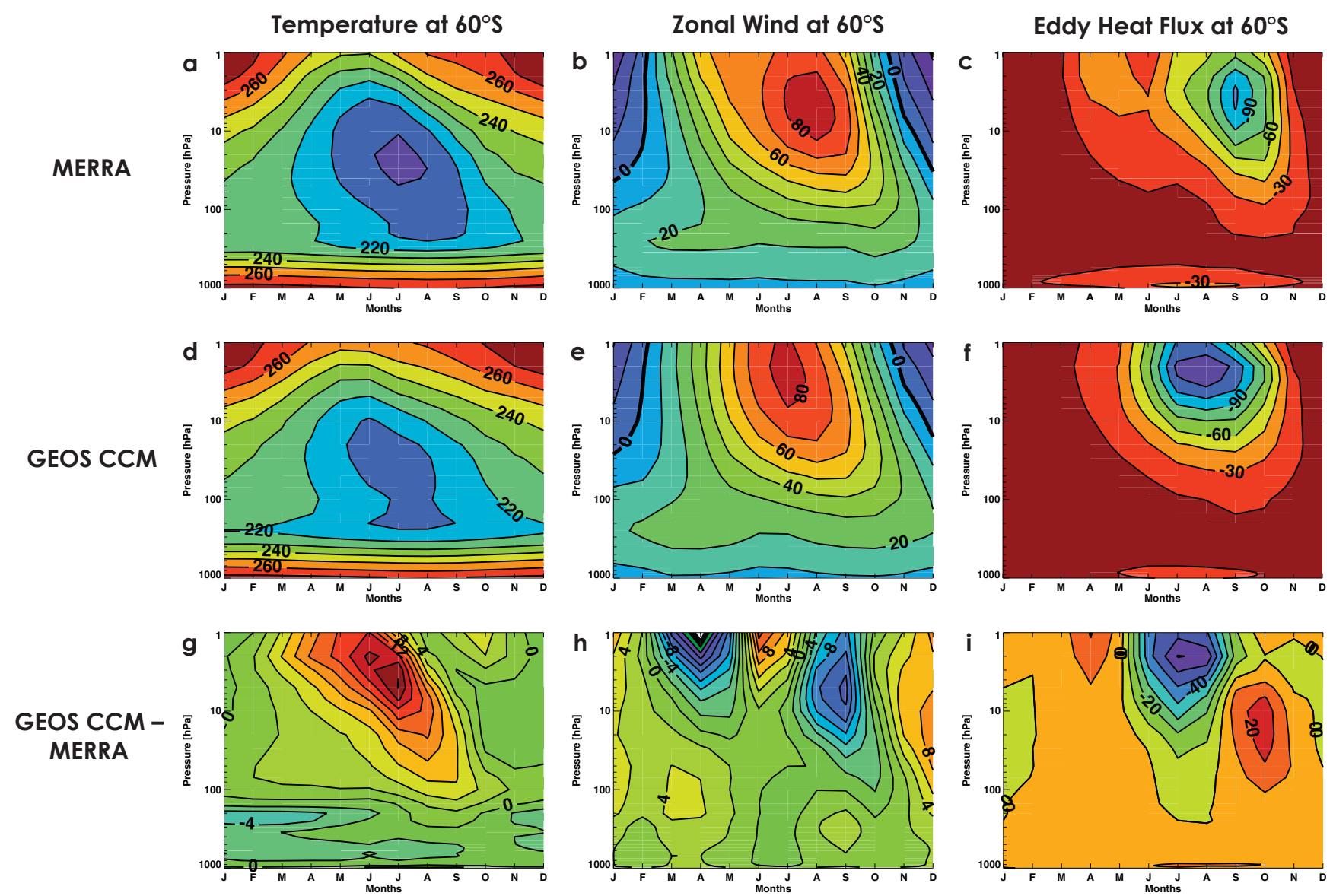

Fig. 1. Temperature $(\mathrm{K})(\mathbf{a}, \mathbf{d}, \mathbf{g})$, zonal wind $\left(\mathrm{m} \mathrm{s}^{-1}\right)(\mathbf{b}, \mathbf{e}, \mathbf{h})$ and meridional eddy heat flux $\left(\mathrm{K} \mathrm{m} \mathrm{s}^{-1}\right)\left(\mathbf{c}, \mathbf{f}\right.$, i) at $60^{\circ} \mathrm{S}$, as a function of month and altitude, in $(\mathbf{a}, \mathbf{b}, \mathbf{c})$ a composite of ENSO neutral years in the MERRA reanalysis, (d, e, f) the ENSON simulation, and (g, $\mathbf{h}, \mathbf{i})$ differences between the ENSON simulation and MERRA.

Heat transfer due to gravity wave breaking is required for the conservation of grid-scale energy across the GWP. Heat transfer is computed from the deposition of the gravity wave energy flux into the mean flow following Warner and McIntyre (2001) and Shaw and Shepherd (2009). In addition, for the conservation of angular momentum and energy, gravity waves stress and energy flux is gradually dissipated in the top five model layers, as suggested by Shaw and Shepherd (2007).

\subsection{GEOS V2 CCM simulations}

Two, 50-yr time-slice simulations with the GEOS V2 CCM will be considered in Sect. 3. Each simulation is forced by a distinct set of SST and sea ice climatologies, each with a repeating annual cycle, with conditions composited from a number of observed WPEN and ENSON events (see Table 1). Each event spans from the July preceding the SONDJF peak in tropical SST anomalies through June of the following year. HadISST1 SSTs and sea ice concentrations at $1^{\circ} \times 1^{\circ}$ resolution (Rayner et al., 2003) are used to prepare the composites. The SSTs used in the WPEN and ENSON simulations are significantly different throughout most of the tropical Pacific.

The set of events used to create the SST and sea ice boundary conditions in the GEOS V2 CCM simulations is slightly different from that used in the MERRA analysis (Table 1). HadISST1 data were not available for the 2008 ENSON and 2009 WPEN events. The 1991 and 1994 WPEN events were associated with large SST anomalies in the central Pacific (Kug et al., 2009) and are thus used to generate a strong model response.

Both simulations use fixed greenhouse gas and ozonedepleting substance boundary conditions representative of the year 2005. Variability related to the solar cycle and volcanic eruptions is not considered. 

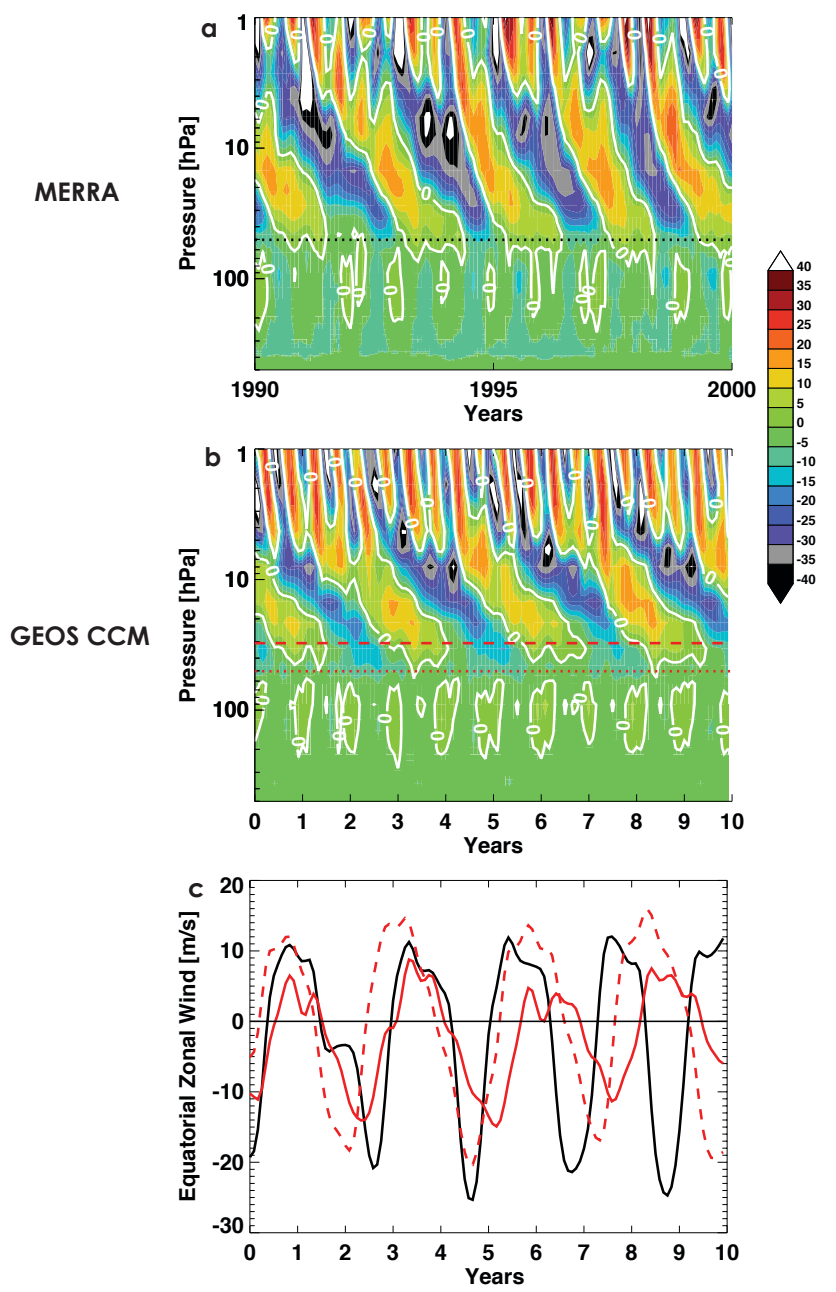

Fig. 2. Equatorial $\left(4^{\circ} \mathrm{S}-4^{\circ} \mathrm{N}\right)$ zonal mean zonal wind $\left(\mathrm{m} \mathrm{s}^{-1}\right)$, as a function of time and altitude: (a) 1990 through 1999 in MERRA; (b) 10 years of the ENSON simulation. White contours denote the zero wind line. The black dotted line highlights the $50 \mathrm{hPa}$ level in MERRA; the red dotted (dashed) line highlights the $50 \mathrm{hPa}(30 \mathrm{hPa})$ level in the ENSON simulation. (c) Smoothed timeseries of equatorial zonal wind at $50 \mathrm{hPa}$ in MERRA (black solid line); $50 \mathrm{hPa}$ in the ENSON simulation (red solid line); $30 \mathrm{hPa}$ in the ENSON simulation (red dashed line).

\section{Results}

\subsection{Climatology of the ENSON simulation}

The mean annual cycles of temperature, zonal wind and eddy heat flux at $60^{\circ} \mathrm{S}$, in the ENSON simulation, are shown in Fig. 1. The MERRA composite of ENSON events is shown for comparison. The GEOS V2 CCM (Fig. 1d) is generally able to simulate the observed stratospheric temperature pattern (Fig. 1a). As has been noted in evaluations of earlier formulations of this model (Pawson et al., 2008; SPARC CCMVal, 2010), polar stratospheric temperatures are biased high in the lower stratosphere in mid-winter (Fig. 1g). Similarly,
Table 2. October/November mean eddy heat flux magnitude $\left(\mathrm{K} \mathrm{m} \mathrm{s}^{-1}\right)$ at $40-80^{\circ} \mathrm{S}, 100 \mathrm{hPa} \pm 2$ standard deviations.

\begin{tabular}{cccc}
\hline ENSO Composite & QBO Phase & MERRA & GEOS CCM \\
\hline WPEN & E & $16.64 \pm 5.09$ & $7.11 \pm 2.27$ \\
& W & $10.22 \pm 2.38$ & $7.86 \pm 4.65$ \\
ENSON & E & $11.12 \pm 3.69$ & $6.54 \pm 3.10$ \\
& W & $11.79 \pm 2.36$ & $6.49 \pm 3.54$ \\
\hline
\end{tabular}

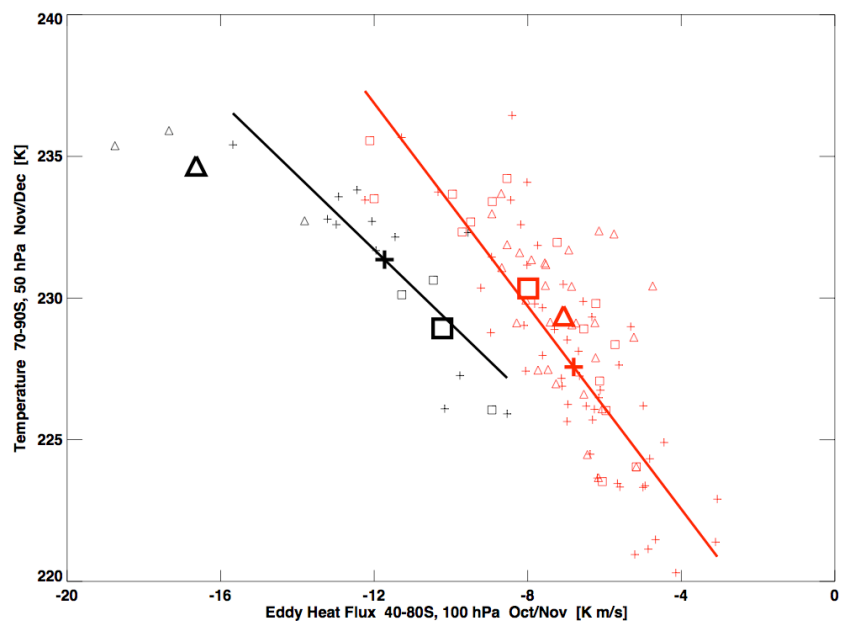

Fig. 3. Scatter plot of October/November meridional eddy heat flux at $40-80^{\circ} \mathrm{S}, 100 \mathrm{hPa}$ versus November/December temperature in the Antarctic polar cap at $50 \mathrm{hPa}$. Red symbols show model results, while black symbols show the MERRA reanalysis. Triangles represent WPEN/QBO-E years; squares represent WPEN/QBO-W years; crosses represent ENSON years. The large symbols show the composite mean values. The red (black) line indicates the linear fit for the modelled (MERRA) ENSON composite.

the model is broadly able to simulate the SH polar jet. Modelled winds (Fig. 1e) remain weaker than observed (Fig. 1b) in the middle stratosphere, in mid- to late winter. Meridional eddy heat flux values are negative throughout the year at $60^{\circ} \mathrm{S}$. Lower stratospheric differences between MERRA and modelled eddy heat flux are small, except in mid-winter (when modelled eddy heat flux is too strong) and in spring (when modelled eddy heat flux is too weak) (Fig. 1h). The simulation of the breakup of the Antarctic vortex is comparable to that reported by Hurwitz et al. (2010).

A timeseries of zonal winds in the equatorial region, in $10 \mathrm{yr}$ of the ENSON simulation, is shown in Fig. 2b. The MERRA timeseries of zonal winds in the 1990s is shown for comparison (Fig. 2a). The modelled QBO has a realistic period $(30 \pm 3$ months, at $30 \mathrm{hPa})$ though the descent of easterly and westerly anomalies from the upper stratosphere is slower than observed. The modelled QBO amplitude is well simulated around $10 \mathrm{hPa}$ but is weaker than observed in the lower stratosphere. Note that the QBO signal is weak 


\section{WPEN/QBO-E - ENSON/QBO-E}

\section{WPEN/QBO-E - WPEN/QBO-W}
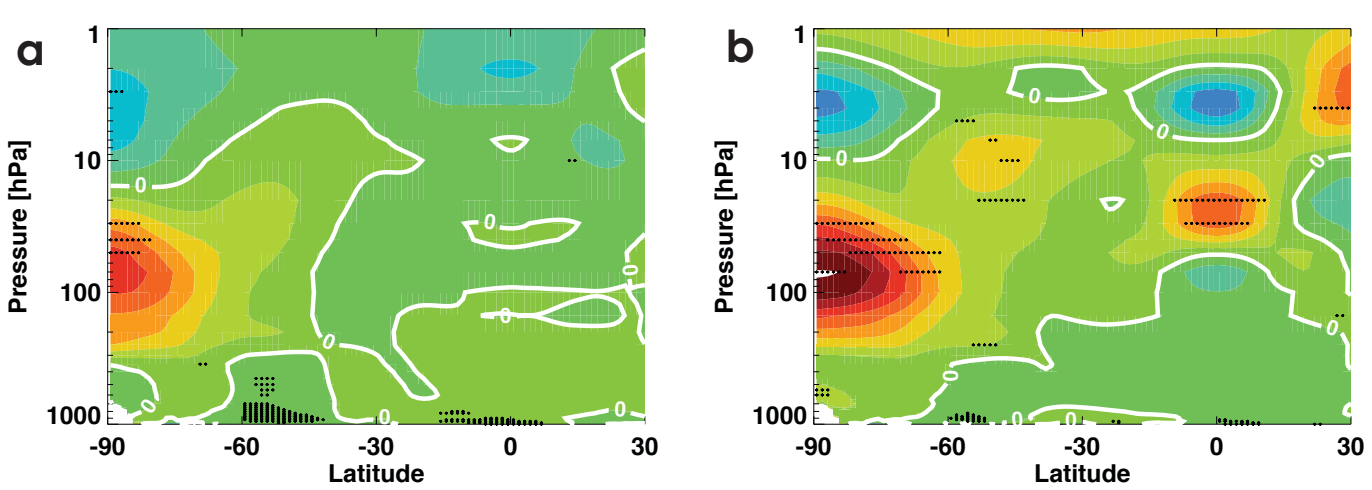

\section{GEOS CCM}
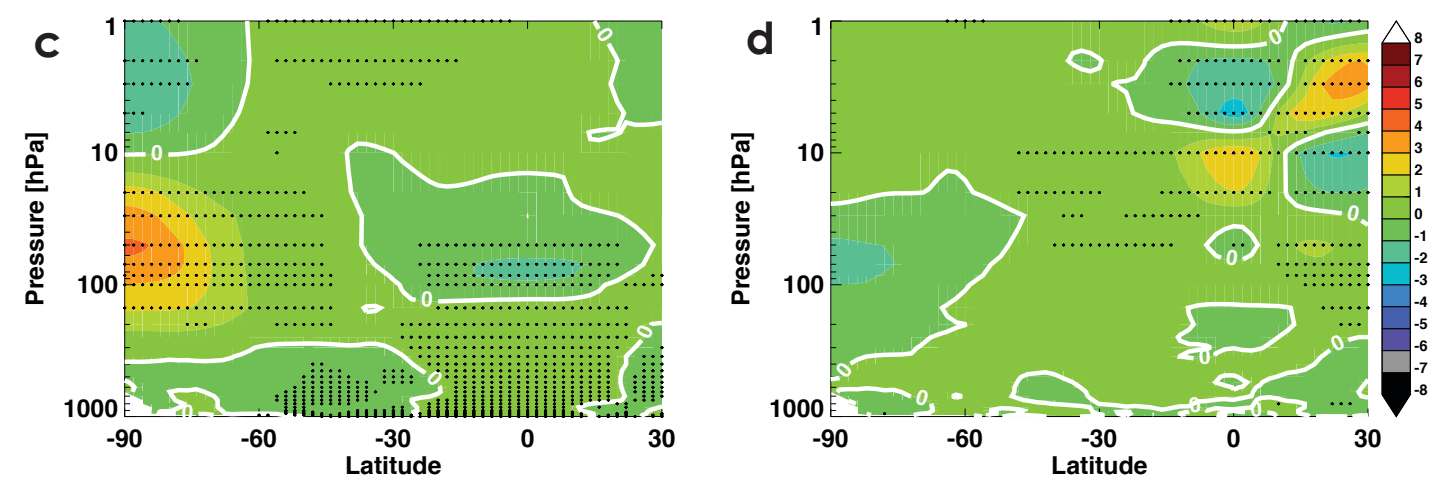

Fig. 4. November/December temperature differences $(\mathrm{K})$ in $(\mathbf{a}, \mathbf{b})$ MERRA and (c, $\mathbf{d})$ the GEOS CCM simulations. The response to WPEN events during QBO-E is shown in (a) and (c). The response to the QBO phase during WPEN events is shown in (b) and (d). White contours indicate zero difference. Black Xs indicate regions where differences are significant at the $95 \%$ confidence level.

at $50 \mathrm{hPa}$ : zonal winds are generally easterly (Fig. 2c). For this reason, $30 \mathrm{hPa}$ zonal winds in the $10^{\circ} \mathrm{S}-10^{\circ} \mathrm{N}$ region are used to characterize the phase of the modelled QBO. As for the MERRA reanalysis, QBO-E years are identified when the modelled November/December mean QBO index is less than $-2 \mathrm{~m} \mathrm{~s}^{-1}$ while QBO-W years are identified when the QBO index is larger than $2 \mathrm{~m} \mathrm{~s}^{-1}$. For each simulation, there are approximately $25 \mathrm{yr}$ designated as QBO-E and $15 \mathrm{yr}$ designated as QBO-W.

\subsection{Stratospheric response to WPEN events}

October/November eddy heat flux at $40-80^{\circ} \mathrm{S}, 100 \mathrm{hPa}$ is a measure of the planetary wave energy entering the SH polar stratosphere (Newman et al., 2001). Table 2 shows composite mean October/November eddy heat flux values for WPEN and ENSON, subdivided by the phase of the QBO. In the MERRA reanalysis, eddy heat flux in the WPEN/QBO-E composite is significantly different than that in all three of the other composites at the $95 \%$ confidence level, in a two-tailed t-test with unequal variance. Though October/November eddy heat flux in the GEOS V2 CCM is weaker than observed (see Hurwitz et al., 2010), the model is able to capture some of the observed variability. For example, eddy heat flux values in the WPEN/QBO-W and ENSON/QBO-W composites are different at the $90 \%$ level. Differences between the modelled WPEN/QBO-E and WPEN/QBO-W composites are not statistically significant. In both the MERRA reanalysis and the GEOS CCM simulations, the magnitude of the eddy heat flux during ENSON events does not depend on the phase of the QBO.

Enhanced eddy heat flux in October/November is associated with a warming of the Antarctic lower stratosphere in November/December (Hurwitz et al., 2011). Eddy heat flux and temperature are well correlated in both MERRA and in the GEOS V2 CCM simulations (Fig. 3). In MERRA, the Antarctic lower stratosphere warms $3-5 \mathrm{~K}$ in response to WPEN events in November/December (Fig. 4a), while the upper stratosphere cools by approximately $1 \mathrm{~K}$. In the Antarctic lower stratosphere, the QBO-related temperature response during WPEN (Fig. 4b) is as large as the WPEN response itself: a $3-8 \mathrm{~K}$ warming that is significantly different from zero at the $95 \%$ confidence level. That is, this warming signal can be attributed to WPEN/QBO-E events. The observed response to the 1991 and 1994 WPEN/QBO-E events was similar (not shown), suggesting that atmospheric 


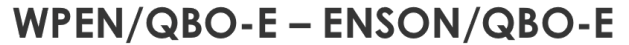

MERRA

\section{GEOS CCM}

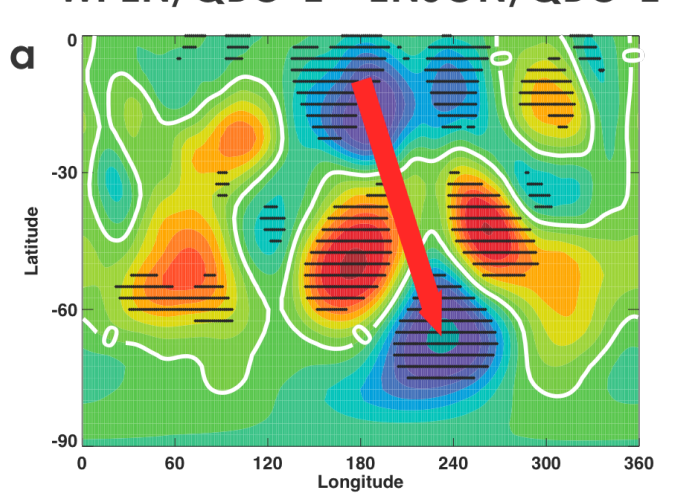

\section{WPEN/QBO-E - WPEN/QBO-W}
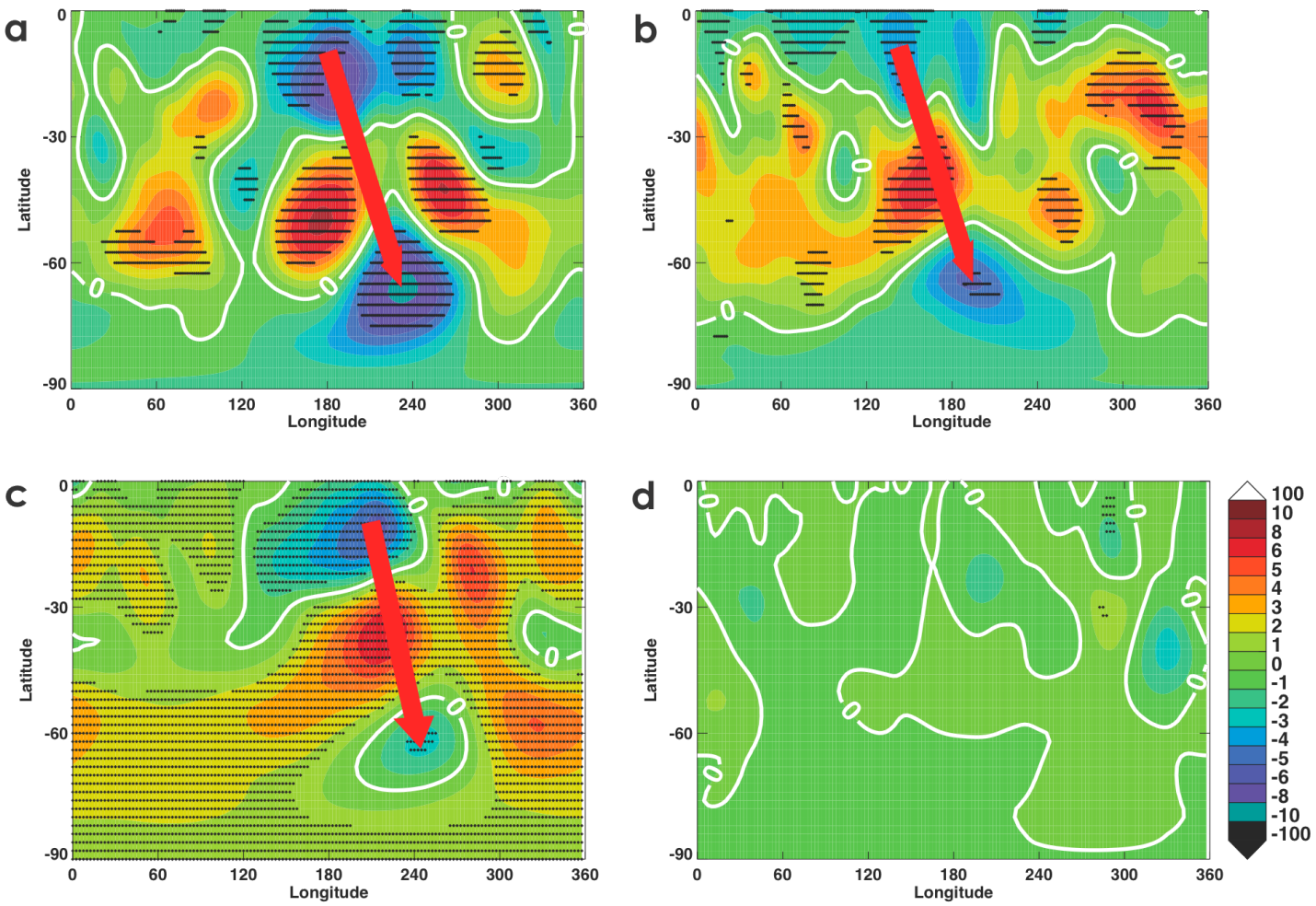

Fig. 5. Longitude-latitude contour plots showing SON seasonal mean streamfunction differences at $250 \mathrm{hPa}\left(10^{-6} \mathrm{~m}^{3} \mathrm{~s}^{-1}\right)$ in (a, b) MERRA and (c, d) the GEOS CCM simulations. The response to WPEN events during QBO-E is shown in (a) and (c). The response to the QBO phase during WPEN events is shown in (b) and (d). White contours indicate zero difference. Black Xs indicate regions where differences are significant at the $90 \%$ confidence level in the MERRA reanalysis and $95 \%$ confidence level in the GEOS CCM. Red arrows indicate the approximate direction of planetary wave propagation.

circulation anomalies associated with the eruption of Mt. Pinatubo did not affect the Antarctic stratosphere to the 1991 WPEN event.

The GEOS V2 CCM is able to simulate the observed Antarctic temperature response to WPEN events, but not the modulation of this response by the QBO. November/December temperature differences between the WPEN and ENSON simulations, during QBO-E, are approximately $2-4 \mathrm{~K}$ in the lower stratosphere with a roughly $1 \mathrm{~K}$ cooling response above $10 \mathrm{hPa}$ (Fig. 4c). Figure $4 \mathrm{~d}$ shows that the modelled temperature response to WPEN is insensitive to the phase of the QBO: the lower stratosphere warms in both QBO-E and QBO-W years.

\subsection{Tropospheric response to WPEN events}

Several tropospheric diagnostics are used to investigate the model's insensitivity to the phase of the QBO: OLR, upper tropospheric streamfunction and calculations of Rossby wave energy in the tropical and subtropical south Pacific. Upper tropospheric streamfunction differences illustrate the planetary wavetrains generated in response to El Niño events. Figure 5 compares the SON seasonal mean streamfunction at $250 \mathrm{hPa}$, in the WPEN versus ENSON cases, as well differences between QBO-E and QBO-W during WPEN events. In the MERRA reanalysis, southeastward-propagating wavetrains are seen in response to both WPEN (Fig. 5a) and the QBO (Fig. 5b). That is, negative streamfunction differences in the tropical central Pacific, positive streamfunction differences at mid-latitudes and negative streamfunction differences near $240^{\circ} \mathrm{E}, 60^{\circ} \mathrm{S}$. The model simulates the wavetrain response to WPEN (Fig. 5c), with comparable magnitude and propagation direction to the MERRA response, but lacks sensitivity to the phase of the QBO (Fig. 5d).

Vera et al. (2004) identified a planetary wave source region in the south central Pacific, during austral spring, in WPENlike events as compared with cold tongue El Niño and ENSO neutral events. The authors determined that the increase in planetary wave activity was the result of enhanced upper level divergence. That is, enhanced convection in the south central Pacific leads to an enhancement in Rossby wave activity and thus to a stronger poleward-propagating wavetrain 
WPEN/QBO-E - ENSON/QBO-E

NOAA
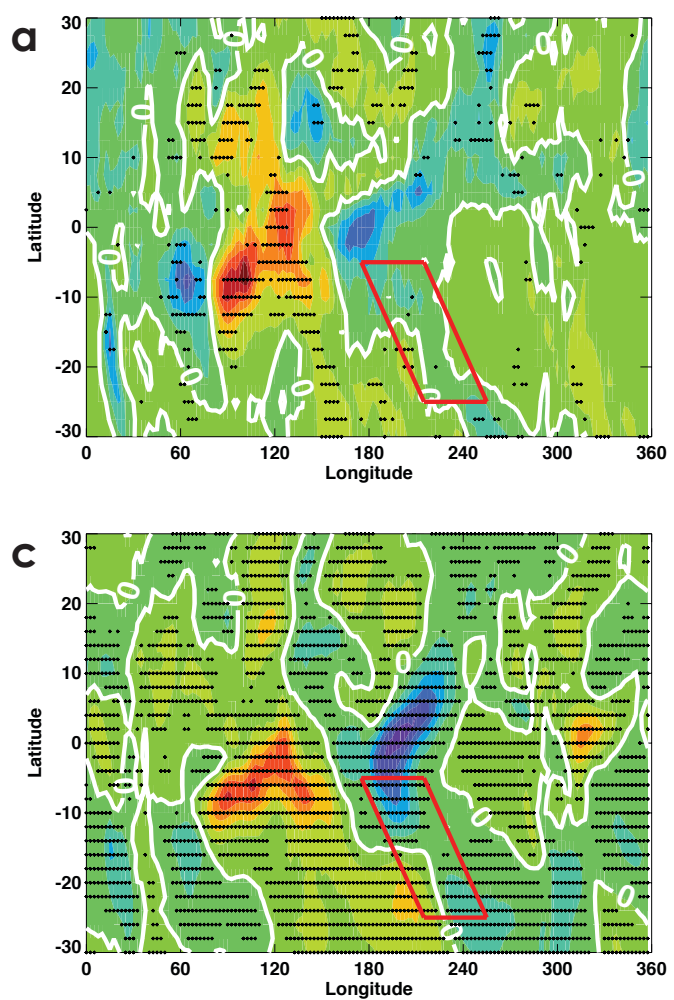

WPEN/QBO-E - WPEN/QBO-W
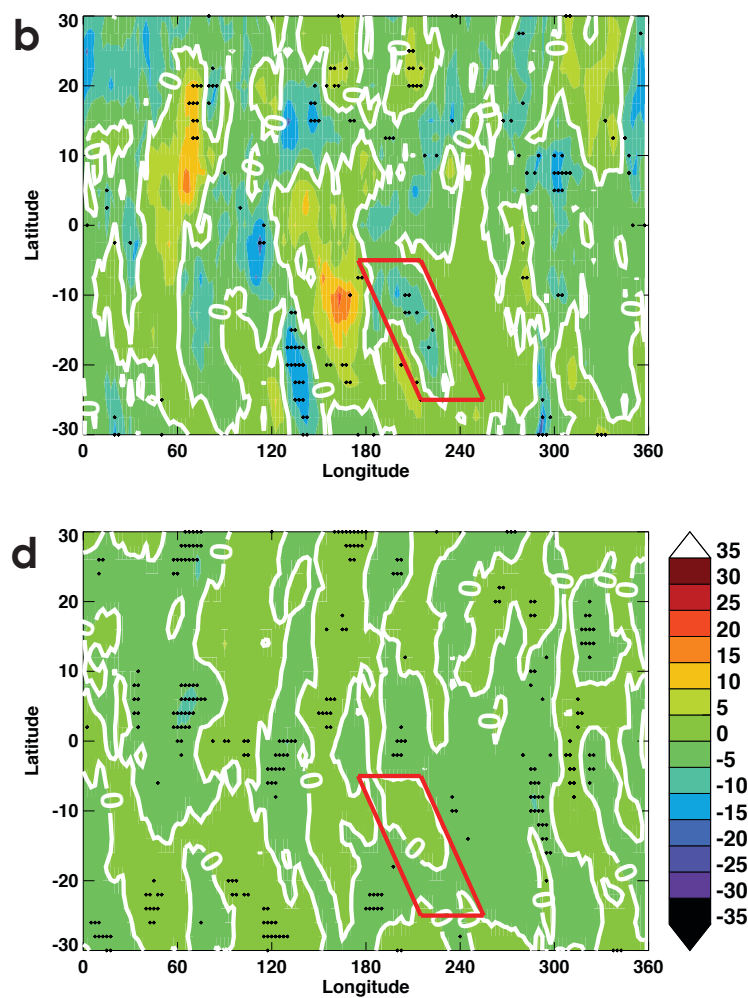

Fig. 6. Longitude-latitude contour plots showing SON seasonal mean OLR differences $\left(\mathrm{W} \mathrm{m}^{-2}\right)$ in (a, b) NOAA and (c, d) the GEOS CCM simulations. The response to WPEN events during QBO-E is shown in (a) and (c). The response to the QBO phase during WPEN events is shown in (b) and (d). White contours indicate zero difference. Black Xs indicate regions where differences are significant at the $90 \%$ confidence level. Red boxes indicate the approximate Rossby wave source region found by Vera et al. (2004).

in the SH. In Fig. 6, OLR differences illustrate changes in convection in the NOAA interpolated OLR dataset and in the GEOS V2 CCM simulations. Negative OLR differences imply relatively higher cloud tops and thus deeper convection. Figure 6a and $\mathrm{c}$ show the convective response to WPEN events, during QBO-E. The largest OLR differences in Fig. 6a and c occur in the equatorial region, and are associated with well-established ENSO-related longitudinal shifts in convection. The convective response to WPEN events extends to the SH subtropics: there are negative OLR differences in the central South Pacific (red boxes) in both the NOAA interpolated OLR dataset (Fig. 6a) and in the model simulations (Fig. 6c).

Observational evidence suggests that QBO-related changes in tropical circulation modulate the depth of convective activity in the subtropics, consistent with the hypothesis of Collimore et al. (2003). There is a distinct region of negative NOAA OLR differences in the Rossby wave source region (indicated by the red boxes) in response to the QBO, during WPEN events (Fig. 6b). In contrast, there are no significant differences in OLR in this region in the model (Fig. 6d).
Planetary wave activity in the central South Pacific is enhanced during observed WPEN events. Figure 7 shows the results of Rossby wave source calculations (based on Jin and Hoskins, 1995) based on upper tropospheric winds from the MERRA reanalysis. The average of the $250 \mathrm{hPa}$ and $300 \mathrm{hPa}$ pressure levels is shown. In WPEN events relative to ENSON (Fig. 7a), and in WPEN/QBO-E events relative to WPEN/QBO-W (Fig. 7b), there is an increase in the Rossby wave source in the region of the red boxes. The regions of increased Rossby wave activity are collocated with decreased OLR (Fig. 6a and b). In the GEOS CCM, there is a relative Rossby wave source in the central Pacific south of $20^{\circ} \mathrm{S}$ during WPEN events (Fig. 7c). However, the modelled response lacks sensitivity to the phase of the QBO (Fig. 7d).

\section{Summary and discussion}

WPEN is an emerging type of El Niño event (Kug et al., 2009). CCMs used to predict ozone recovery and the $21^{\text {st }}$ century stratospheric climate need to capture the extratropical stratospheric response to WPEN, since these events 


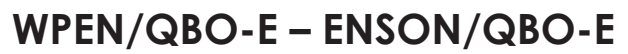

MERRA

\section{GEOS CCM}

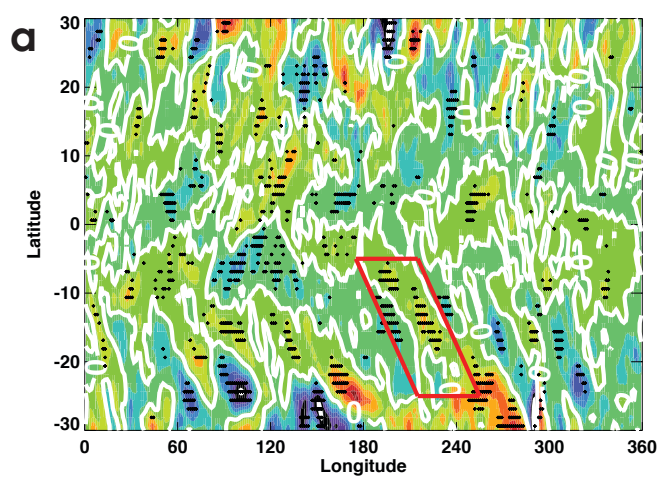

WPEN/QBO-E - WPEN/QBO-W
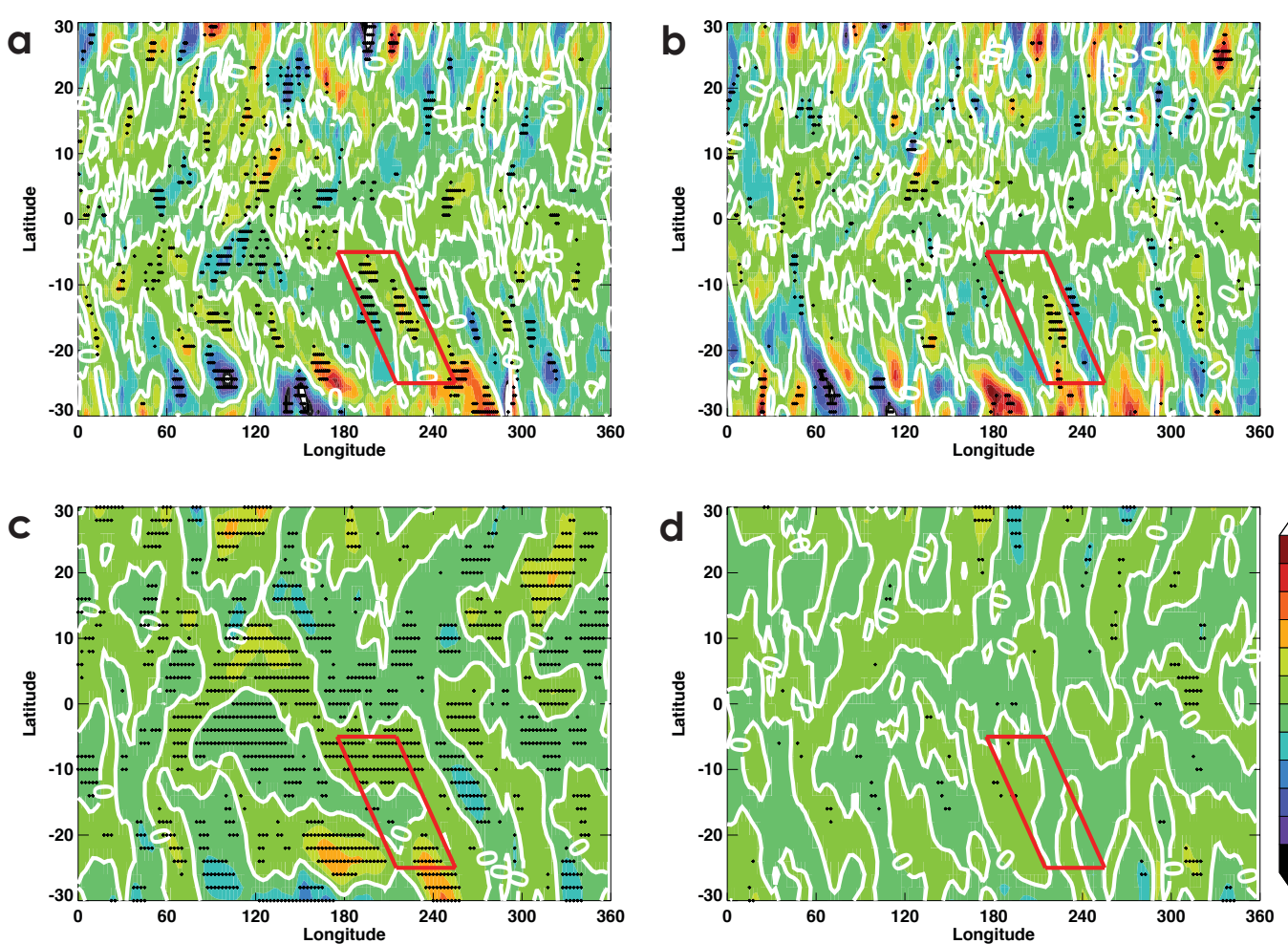

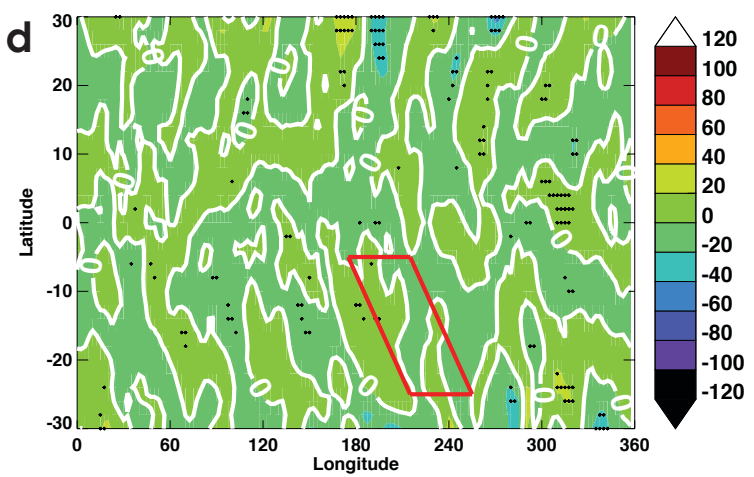

Fig. 7. Longitude-latitude contour plots showing SON seasonal mean differences in the Rossby wave source $\left(10^{10} \mathrm{~s}^{-2}\right)$, as described in the text, in (a, b) MERRA and (c, d) the GEOS CCM simulations. The response to WPEN events during QBO-E is shown in (a) and (c). The response to the QBO phase during WPEN events is shown in (b) and (d). White contours indicate zero difference. Black Xs indicate regions where differences are significant at the $95 \%$ confidence level. Red boxes indicate the approximate Rossby wave source region found by Vera et al. (2004).

are predicted to occur more frequently in future (Yeh et al., 2009; Xie et al., 2010).

This study was the first to examine the modelled response of the Antarctic stratosphere to WPEN, as well as the modulation of this response by the QBO. Two time-slice simulations, one representing WPEN conditions and the other ENSON conditions, were used to both test a new formulation of the GEOS V2 CCM and confirm the observed atmospheric response to recent WPEN events (as described by Hurwitz et al., 2011). The MERRA reanalysis was directly compared with the modelled response to WPEN.

WPEN events enhanced poleward planetary wave activity in the central South Pacific during austral spring. In both MERRA and in the GEOS V2 CCM, enhanced eddy heat flux led to a relative warming of the Antarctic lower stratosphere in November/December. During QBO-E, the GEOS V2 CCM simulated a warming of $2-4 \mathrm{~K}$ in the Antarctic lower stratosphere, in the WPEN simulation relative to ENSON. The modelled temperature response to WPEN events had the same vertical and meridional structure but was somewhat weaker than that in the MERRA reanalysis (3-5 K). The relatively weaker model response is likely a consequence of the experimental design: This study compared the transient atmospheric response (i.e., in the MERRA reanalysis) with time-slice simulations, each representing a near-equilibrium climate.

Analysis of MERRA demonstrated the sensitivity of the WPEN response to the phase of the QBO, in the 1979-2009 period. The lower stratospheric WPEN-related warming signal was as large as the QBO-related warming signal, suggesting that this signal could be attributed to WPEN events coincident with the easterly phase of the QBO. Tropospheric diagnostics suggest that it was the combination of the placement of convective activity in the subtropical Pacific during WPEN events, and the enhancement of this convective activity during QBO-E, that led to changes in planetary wave activity in the $\mathrm{SH}$ and thus to the stratospheric temperature response.

In the GEOS V2 CCM simulations, the Antarctic temperature response to WPEN events was insensitive to the phase of the QBO. OLR, streamfunction and Rossby wave source diagnostics demonstrated that the modelled QBO signal did 
not extend far enough into the lower stratosphere and upper troposphere to modulate convection and thus planetary wave activity in the south central Pacific. In the model formulation examined in this study, zonal winds in the lower stratosphere (i.e., $50 \mathrm{hPa}$ ) were predominantly easterly, regardless of the phase of the QBO at higher altitudes (i.e., $30 \mathrm{hPa}$ ). Thus, the model produced an easterly QBO-like response to WPEN in both phases of the middle stratospheric QBO. The persistent QBO-E response to WPEN events biases precipitation and convection in the central South Pacific, in turn suppressing interannual variability in the Antarctic stratosphere. If the QBO westerly anomalies were to descend further into the lower stratosphere and/or or upper troposphere, better matching observations, the model would likely be able to simulate QBO-related modulation of subtropical convection and in turn the dependence of the WPEN response on the QBO phase.

Acknowledgements. The authors thank Chaim Garfinkel for the Rossby wave source calculations, NASA's MAP program for funding, and two anonymous reviewers for their helpful comments. MMH acknowledges support from the NASA Postdoctoral Program at Goddard Space Flight Center, administered by Oak Ridge Associated Universities through a contract with NASA.

Edited by: A. J. G. Baumgaertner

\section{References}

Alexander, M. J., and Teitelbaum, H.: Observation and analysis of a large amplitude mountain wave event over the Antarctic peninsula, J. Geophys. Res., 112, D21103, doi:10.1029/2006JD008368, 2007.

Alexander, M. J., Eckermann, S. D., Broutmann, D., and Ma, J.: Momentum flux estimates for South Georgia Island mountain waves in the stratosphere observed via satellite, Geophys. Res. Lett., 36, L12816, doi:10.1029/2009GL038587, 2009.

Ashok, K., Behera, S. K., Rao, S. A., Weng, H., and Yamagata, T.: El Niño Modoki and its possible teleconnections, J. Geophys. Res., 112, C11007, doi:10.1029/2006JC003798, 2007.

Bacmeister, J. T., Suarez, M. J., and Robertson, F. R.: Rain reevaporation, boundary-layer/convection interactions and Pacific rainfall patterns in an AGCM, J. Atmos. Sci., 63, 3383-3403, 2006.

Baldwin, M. P, and Dunkerton, T. J.: Quasi-biennial modulation of the southern hemisphere stratospheric vortex, Geophys. Res. Lett., 25, 3343-3346, 1998.

Bosilovich, M.: NASA'S modern era retrospective-analysis for research and applications: integrating earth observations, Earthzine, 26 September 2008.

Bloom, S., da Silva, A., Dee, D., Bosilovich, M., Chern, J.-D., Pawson, S., Schubert, S., Sienkiewicz, M., Stajner, I., Tan, W.-W., and $\mathrm{Wu}, \mathrm{M}$.-L.: Documentation and validation of the Goddard Earth-Observing System (GEOS) Data Assimilation System Version 4, Tech. Rep. 104606, V26, NASA, Greenbelt, Maryland, USA, 2005.

Bronnimann, S., Luterbacher, J., Staehelin, J., Svendby, T. M., Hansen, G., and Svene, T.: Extreme climate of the global tro- posphere and stratosphere in 1940-42 related to El Niño, Nature, 431, 971-974, doi:10.1038/nature02982, 2004.

Cagnazzo, C., Manzini, E., Calvo, N., Douglass, A., Akiyoshi, H., Bekki, S., Chipperfield, M., Dameris, M., Deushi, M., Fischer, A. M., Garny, H., Gettelman, A., Giorgetta, M. A., Plummer, D., Rozanov, E., Shepherd, T. G., Shibata, K., Stenke, A., Struthers, H., Tian, W.: Northern winter stratospheric temperature and ozone response to ENSO inferred from an ensemble of Chemistry Climate Models, Atmos. Chem. Phys., 9, 8935-8948, doi:10.5194/acp-9-8935-2009, 2009.

Chou, M.-D. and Suarez, M. J.: A Solar Radiation Parameterization for Atmospheric Studies, NASA Technical Report Series on Global Modeling and Data Assimilation 104606, 15, 40 pp., 1999.

Chou, M.-D., Suarez, M. J., Liang, X. Z., and Yan, M. M.-H.: A Thermal Infrared Radiation Parameterization for Atmospheric Studies, NASA Technical Report Series on Global Modeling and Data Assimilation 104606, 19, 56 pp., 2001.

Collimore, C. C., Martin, D. W., Hitchman, M. H., Huesman, A., and Waliser, D. E.: On the relationship between the QBO and tropical deep convection, J. Climate, 16, 2552-2568, 2003.

Free, M. and Seidel, D. J.: Observed El Niño-Southern Oscillation temperature signal in the stratosphere, J. Geophys. Res., 114, D23108, doi:/10.1029/2009JD012420, 2009.

Garcia, R. R. and Solomon, S.: The effect of breaking gravity waves on the dynamics and chemical composition of the mesosphere and lower thermosphere, J. Geophys. Res., 90, 3850-3868, 1985.

Garfinkel, C. I. and Hartmann, D. L.: Effects of the El NiñoSouthern Oscillation and the Quasi-Biennial Oscillation on polar temperatures in the stratosphere, J. Geophys. Res., 112, D19112, doi:10.1029/2007JD008481, 2007.

Garfinkel, C. I., and Hartmann, D. L.: Different ENSO teleconnections and their effects on the stratospheric polar vortex, J. Geophys. Res., 113, D18114, doi:10.1029/2008JD009920, 2008.

Helfand, H. M. and Schubert, S. D.: Climatology of the simulated Great Plains low-level jet and its contribution to the continental moisture budget of the United States, J. Climate, 8, 784-806, 1995.

Hurwitz, M. M., Newman, P. A., Li, F., Oman, L. D., Morgenstern, O., Braesicke, P., and Pyle, J. A.: Assessment of the breakup of the Antarctic polar vortex in two new chemistry-climate models, J. Geophys. Res., 115, D07105, doi:10.1029/2009JD012788, 2010.

Hurwitz, M. M., Newman, P. A., Oman, L. D., and Molod, A. M.: Response of the Antarctic Stratosphere to two Types of El Niño events, J. Atmos. Sci., 68, 812-822, 2011.

Jin, F.-F. and Hoskins, B. J.: The direct response to tropical heating in a baroclinic atmosphere, J. Atm. Sci., 52, 307-319, 1995.

Koster, R. D., Suarez, M. J., Ducharne, A., Stieglitz, M., and Kumar, P.: A catchment-based approach to modeling land surface processes in a GCM, Part 1, Model Structure, J. Geophys. Res., 105, 24809-24822, 2000.

Kug, J.-S., Jin, F.-F., and An, S.-I.: Two types of El Nino events: cold tongue El Niño and warm pool El Niño, J. Climate, 22, 1499-1515, 2009.

Larkin, N. K. and Harrison, D. E.: On the definition of El Niño and associated seasonal average U.S. weather anomalies, Geophys. Res. Lett., 32, L13705, doi:10.1029/2005GL022738, 2005.

Liebmann, B. and Smith, C. A.: Description of a complete (inter- 
polated) outgoing longwave radiation dataset, B. Am. Meteorol. Soc., 77, 1275-1277, 1996.

Lin, S.-J.: A vertically Lagrangian finite-volume dynamical core for global models, Mon. Weather Rev., 132, 2293-2307, 2004.

Lindzen, R. S.: Turbulence and stress owing to gravity wave and tidal breakdown, J. Geophys. Res., 86, 9707-9714, 1981.

Lock, A. P., Brown, A. R., Bush, M. R., Martin, G. M., and Smith, R. N. B.: A new boundary layer mixing scheme. Part I: Scheme description and single-column model tests, Mon. Weather Rev., 138, 3187-3199, 2000.

Louis, J., Tiedtke, M., and Geleyn, J.: A short history of the PBL parameterization at ECMWF, Proc. ECMWF Workshop on Planetary Boundary Layer Parameterization, Reading, United Kingdom, ECMWF, 59-80, 1982.

Manzini, E., Giorgetta, M. A., Esch, M., Kornblueh, L., and Roeckner, E.: The influence of sea surface temperatures on the Northern winter stratosphere: ensemble simulations with the MAECHAM5 model, J. Climate, 19, 3863-3881, 2006.

McFarlane, N. A.: The effect of orographically excited gravitywave drag on the circulation of the lower stratosphere and troposphere, J. Atmos. Sci., 44, 1775-1800, 1987.

Molod, A. M., Takacs, L., Suarez, M., Bacmeister, J., Song, I.-S., Eichmann, A., and Chang, Y.: The GEOS-5 Atmospheric General Circulation Model: Mean Climate and Development from MERRA to Fortuna, Tech. Rep. 104606, V28, Greenbelt, Maryland, USA, in preparation, 2011.

Moorthi, S. and Suarez, M. J.: Relaxed Arakawa-Schubert, A Parameterization of Moist Convection for General-Circulation Models, Mon. Weather Rev., 120, 978-1002, 1992.

Newman, P. A. and Nash, E. R.: The unusual Southern Hemisphere stratosphere winter of 2002, J. Atmos. Sci., 62, 614-626, 2005.

Newman, P. A., Nash, E. R., and Rosenfield, J. E.: What controls the temperature of the Arctic stratosphere during the spring?, J. Geophys. Res., 106, 19999-20010, 2001.

Pawson, S., Stolarski, R. S., Douglass, A. R., Newman, P. A., Nielsen, J. E., Frith, S. M., and Gupta, M. L.: Goddard Earth Observing System chemistry-climate model simulations of stratospheric ozone-temperature coupling between 1950 and 2005, J. Geophys. Res., 113, D12103, doi:10.1029/2007JD009511, 2008.

Rasmusson, E. M. and Carpenter, T. H.: Variation in tropical sea surface temperature and surface wind fields associated with Southern Oscillation/El Niño, Mon. Weather Rev., 110, 354-384, 1982.

Rayner, N. A., Parker, D. E., Horton, E. B., Folland, C. K., Alexander, L. V., Rowell, D. P., and Kaplan, A.: Global analyses of sea surface temperature, sea ice, and night marine air temperature since the late nineteenth century, J. Geophys. Res., 108, 4407, doi:10.1029/2002JD2670, 2003.
Richter, J. H., Sassi, F., and Garcia, R. R.: Toward a physically based gravity wave source parameterization in a general circulation model, J. Atmos. Sci., 67, 136-156, 2010.

Rienecker, M. M., Suarez, M. J., Gelaro, R., Todling, R., Bacmeister, J., Liu, E., Bosilovich, M. G., Schubert, S. D., Takacs, L., Kim, G.- K., Bloom, S., Chen, J., Collins, D., Conaty, A., da Silva, A., Gu, W., Joiner, J., Koster, R. D., Lucchesi, R., Molod, A. M., Owens, T., Pawson, S., Pegion, P., Redder, C. R., Reichle, R., Robertson, F. R., Ruddick, A. G., Sienkiewicz, M., and Woollen, J.: MERRA - NASA's Modern- Era Retrospective, Anal. Res. Appl., J. Climate, 24, 3624-3648, doi:10.1175/JCLID-11-00015.1, 2011.

Sassi, F., Kinnison, D., Boville, B. A., Garcia, R. R., and Roble, R.: Effect of El Niño-Southern Oscillation on the dynamical, thermal, and chemical structure of the middle atmosphere, J. Geophys. Res., 94, 14705-14716, doi:10.1029/JD094iD12p14705, 2004.

Shaw, T. A. and Shepherd, T. G.: Angular momentum conservation and gravity wave drag parameterization: Implications for climate models, J. Atmos. Sci., 64, 190-203, 2007.

Shaw, T. A. and Shepherd, T. G.: A theoretical framework for energy and momentum consistency in subgrid-scale parameterization for climate models, J. Atmos. Sci., 66, 3095-3114, 2009.

SPARC CCMVal: SPARC Report on the Evaluation of ChemistryClimate Models, edited by: Eyring, V., Shepherd, T. G., and Waugh, D. W., SPARC Report No. 5, WCRP-132, WMO/TDNo. 1526, available online at: http://www.atmosp.physics. utoronto.ca/SPARC, 2010

Vera, C., Silvestri, G., Barros, V., and Carril, A.: Differences in El Niño response over the Southern Hemisphere, J. Climate, 17, 1741-1753, 2004.

Warner, C. D. and McIntyre, M. E.: An ultrasimple spectral parameterization for nonorographic gravity waves, J. Atmos. Sci., 58 , 1837-1857, 2001.

Xie, S.-P., Deser, C., Vecchi, G. A., Ma, J., Teng, H. Y., and Wittenberg, A. T.: Global warming pattern formation: sea surface temperature and rainfall, J. Climate, 23, 966-986, 2010.

Yeh, S.-W., Yim, B. Y., Noh, Y., and Dewitte, B.: Changes in mixed layer depth under climate change projections in two CGCMs, Clim. Dynam., 33, 199-213, 2009.

Ziemke, J. R., Chandra, S., Oman, L. D., and Bhartia, P. K.: A new ENSO index derived from satellite measurements of column ozone, Atmos. Chem. Phys., 10, 3711-3721, doi:10.5194/acp-86365-2010, 2010 